\title{
Razão prática e Meta-ética: uma análise a partir da Fundamentação da Metafísica dos Costumes de Kant
}

\author{
Practical reason and Metaethics: $a$ analysis of Kant's \\ Groundwork of the Metaphysics of Morals
}

\section{Marta Nunes da Costa*}

Universidade Federal do Mato Grosso do Sul (UFMS), Campo Grande, MS, Brasil

\section{Resumo}

A Fundamentação da Metafísica dos Costumes constitui um projeto específico de Kant, a saber, o projeto de determinar o princípio supremo da moralidade apenas. Kant não pretende com a Fundamentação oferecer um guia completo para a ação - e assim responder à questão "o que devo fazer?" - mas antes oferecer a fundamentação necessária para uma ética normativa. Neste sentido podemos dizer que a Fundamentação tenta responder a questões de segunda-ordem, geralmente do domínio da meta-ética, ou seja, o autor busca identificar a fonte da legitimidade da própria moral. Neste artigo quero defender a leitura de que a Fundamentação parece estar suspensa entre um projeto ético-normativo e um projeto meta-ético. Projeto ético-normativo, na medida em que Kant identifica e afirma a existência de uma verdade moral que se apresenta geralmente de forma obscura ao ser humano, já que este é influenciado por desejos e intuições naturais. $O$ método a priori

* MNC: Doutorada em Ciência Política e Filosofia Política, e-mail: nunesdacosta77@gmail.com 
de análise pretende trazer à superfície a verdade universal que todos os seres humanos têm o potencial de reconhecer como "suas", i.e., uma verdade universal que se manifesta no reconhecimento (mesmo que através da postulação) da autonomia individual como exercício concreto da razão. O reconhecimento desta verdade permite-nos determinar como devemos agir, estabelecendo o critério que nos permite diferenciar uma ação moral de uma ação imoral. Por outro lado, a Fundamentação caracteriza simultaneamente, uma posição meta-ética, na medida em que a postulação desta verdade universal representa o culminar de um processo mais radical de questionamento das condições de possibilidade da própria moral. Assim, o objetivo deste artigo é articular os argumentos éticos e meta-éticos presentes na Fundamentação, mostrando que estes representam preocupações ou pontos de vista distintos mas que, em última análise, se pressupõem mutuamente.

Palavras-chave: Ética. Meta-ética. Kant. Liberdade. Autonomia.

\section{Abstract}

The Groundwork for the Metaphysics of Morals represents a specific project by Kant, namely, the project of determining the supreme principle of morality. Kant does not intend to offer a complete guide for action, therefore answering the question "what should I do?". Instead, Kant offers the necessary groundwork for a normative ethics. Under this light, one may say that the Groundwork tries to answer a second-order set of questions, given that the author tries to identify the source of legitimacy of morals itself. In this article I argue that the Groundwork should be read as a normative project on the one hand, and a meta-ethics project, on the other. A normative project insofar Kant affirms the existence of a moral truth, generally obscure to most human beings who are naturally influenced by desires and inclinations. The a priori method of analysis brings to the surface the universal truth to which all human beings have access. The recognition of this truth allows one to determine how to act, establishing the criterion of differentiation between moral and immoral actions. On the other hand, the Groundwork can be seen as a meta-ethical position, insofar the postulation of this universal truth represents the culmination of a more radical process of questioning about the conditions of possibility of morality itself. Therefore, the goal of this article is to articulate ethical and meta-ethical arguments as exposed in the Groundwork, showing how each type of arguments represent a distinct point of view, which, nonetheless, must presuppose each other.

Keywords: Ethics. Metaethics. Kant. Freedom. Autonomy. 


\section{Introdução}

\section{A necessidade de uma Fundamentação}

Falar de ação humana é falar da experiência da ação, do exercício da ação no mundo. Assim, sempre que nos referimos a ações está implícito o mundo sobre o qual essas ações se debruçam. Num primeiro momento, poderia parecer que uma ética normativa, i.e., um conjunto de princípios que nos diz como devemos agir, e por que a sua proposta é justificada, tem que ter uma base ou fundamentação empírica. A ação é ação no mundo e sobre o mundo, as motivações - i.e., o que desencadeia a ação - são motivações acerca do mundo e a justificação, de alguma forma, reflete a relação entre o sujeito e o mundo como objeto, e supõe um "fim". Para os utilitaristas, o fim da ação é a felicidade, ou a promoção do prazer e a eliminação ou redução de dor. O critério que nos permite avaliar a moralidade da ação é o conceito de promoção de felicidade. Mas como definir "felicidade"? O século XX, a partir dos Principia Ethica de Moore (1903), teve que confrontar este desafio, nomeadamente, o desafio de oferecer uma definição para um conceito, que é critério de correção moral. Moore fala do "bem" e mostra como o "bem" é indefinível, irredutível a uma propriedade natural, mas que mesmo assim é possível conhecê-lo por intuição. Por isso, Moore é um não-naturalista, mas, cognitivista. Acreditar que se pode conhecer a moralidade da ação significa que tem de ser possível determinar o valor de verdade do juízo moral. Porém, como a intuição é postulada e não é, em última análise, verificável, isto levanta um problema sério para aqueles que querem defender um tipo de intuicionismo.

Kant, que escreveu no final do século XVIII, não toma a linguagem como paradigma a partir do qual se pensam os problemas filosóficos. A virada linguística viria apenas no inicio do século XX com Frege, Russell, Wittgenstein, entre outros filósofos analíticos. Porém, Kant tem consciência dos problemas que orientam as reflexões meta-éticas contemporâneas, na medida em que: 
a) Kant reconhece que "os próprios costumes ficam sujeitos a toda a sorte de perversão enquanto lhes faltar aquele fio condutor e norma suprema do seu exato julgamento" (KANT, 2007, p. 16), isto é, é preciso justificar os valores para que a comunidade de seres humanos os reconheça como princípios de conduta moral;

b) mas antes de justificar os valores temos de determinar o carácter desses valores, ou seja, é preciso clarificar o valor que deve orientar a ação humana. Que valor é esse? Será que pode ser a felicidade? Para Kant é evidente que a felicidade não pode fornecer um critério de correção moral. Em vista que a felicidade é indefinível, i.e., é impossível determinar o conteúdo do conceito de forma absoluta, porque o conteúdo varia conforme a circunstância e o indivíduo. A dificuldade trazida, ou manifesta, pelo conceito de felicidade deriva do facto deste apontar para uma realidade empírica, transmutável. Logo, se a realidade empírica muda, o conceito de felicidade também muda, consoante ao conteúdo que se lhe queira atribuir. Se queremos recuperar o espaço para uma moral, é necessário buscar e identificar o princípio supremo da moralidade de forma totalmente a priori, i.e., independente da experiência. Como Kant diz no Prefácio da Fundamentação, "[a] lei moral, na sua pureza e autenticidade ... não se deve buscar em nenhuma outra parte senão numa filosofia pura, e esta (Metafísica) tem que vir portanto em primeiro lugar, e sem ela não pode haver em parte alguma uma Filosofia moral..." (KANT, 2007, p. 17). Só há filosofia moral propriamente dita se esta tiver como objeto um princípio puro, a priori. Isto exclui todas as pretensas filosofias morais do estatuto de filosofia; quando muito, seriam ramos da psicologia empírica ou da antropologia. Daí que “[a] Metafísica dos Costumes deve investigar a ideia e os princípios duma possível vontade pura, e não as ações e condições do querer humano em geral, as quais são tiradas na maior parte da Psicologia"' (idem, meu itálico).

Percebemos desde o início que, afinal, uma das obras mais emblemáticas da história da filosofia, muitas vezes utilizada como exemplo 
de teoria moral ou ética normativa substantiva, se apresenta como um desafio que hoje consideraríamos como específico da meta-ética, já que Kant não quer responder à questão "como devo agir?", mas, antes, “porque devo agir de x forma?". Não se trata apenas de apresentar argumentos a favor de determinado núcleo de princípios morais, mas, mostrar porque a própria discussão acerca do conteúdo destes princípios só pode ser feita se for dada anteriormente a prova de que a moral é necessária, ou, por outras palavras numa acepção contemporânea, que faz sentido falar de moral.

O que consideramos hoje como ética contemporânea pertenceria, de acordo com Kant, ao domínio da Psicologia, mas não da Filosofia, na medida em que se mostra incapaz de distinguir analiticamente os diferentes tipos de motivação, nomeadamente, os motivos que se apresentam a priori pela razão apenas e os motivos empíricos, que se prendem a experiências concretas. Esta incapacidade gera uma confusão imensa e, progressivamente impossibilita, ou pelo menos dificulta, o processo de reconhecimento do valor moral das nossas ações. Como a maioria dos seres humanos está numa situação em que não consegue discernir claramente as suas prioridades representando o seu próprio fim de forma errada, i.e., como a maioria dos seres humanos tende a ceder aos critérios normativos estabelecidos do status quo de forma a promover apenas os seus interesses contingentes, é preciso esclarecer, ou melhor, trazer à luz o princípio supremo da moralidade. Por isso, a Fundamentação é um passo anterior à Crítica da razão pura prática, e é sua condição de possibilidade, na medida em que por um lado, afirma a unidade da razão e mostra como a razão tem aplicações distintas (aplicação teórica e prática); por outro lado, “[...] nada mais é do que a busca e fixação do princípio supremo da moralidade, o que constitui só por si no seu propósito uma tarefa completa e bem distinta de qualquer outra investigação moral" (KANT, 2007, p. 19). Uma vez clarificado o princípio supremo da moralidade - que supõe o reconhecimento da partilha de faculdades racionais por todos os sujeitos, logo impõe a capacidade de agir moralmente por parte de todos - podemos proceder à Crítica propriamente dita. 
Assim, com a Fundamentação da Metafísica dos Costumes, Kant quer estabelecer as condições de possibilidade para um exercício prático da razão, semelhantes as da Crítica da Razão Pura, que estabelece a crítica como método e fator determinante para identificar não só as faculdades da razão mas as competências de cada uma delas, devem ser buscadas e determinadas a priori. Só retirando os componentes empíricos da ação e motivação da ação moral é possível vislumbrar a unidade da razão que Kant postula e que, com a crítica, ganha consciência dos seus limites e domínios específicos.

O reconhecimento de que a Fundamentação se desdobra em dois projetos distintos mas complementares (um projeto ético-normativo e um projeto meta-ético) traz consigo à tona uma série de outras questões, geralmente negligenciadas, que precisam ser respondidas.

Seguindo a topologia de Miller (2003) a meta-ética contemporânea orienta-se a partir de conjuntos distintos de questões:

1. A questão do sentido/ função semântica do discurso moral;

2. A questão metafísica, que tenta identificar se existem fatos ou propriedades morais e, em caso afirmativo, que tipo de fatos ou propriedades são;

3. A questão da justificação, que procura perceber como justificamos o nosso 'conhecimento' moral e pensa os juízos morais como passiveis de atribuição de valor de verdade;

4. A questão das qualidades morais no mundo;

5. A questão da motivação do agente e daquele que pronuncia juízos morais; e

6. A questão da objetividade, onde se tenta chegar (ou não) a uma 'verdade moral' (MILLER, 2003, p. 2).

A forma como estas questões estão definidas e compartimentalizadas sugere a aceitação de alguns postulados que Kant, à partida, negaria. Por exemplo, Kant afirma a distinção entre o uso teórico e o uso prático da razão, o que torna a questão do "conhecimento moral" um pseudoproblema, ou melhor, o problema que conduz a razão às antinomias. Não entrarei aqui, no debate específico de cada uma delas. Porém, é importante ter em mente estes conjuntos de questões para perceber como Kant responde a algumas delas, mesmo que 
transformando-as a partir de uma mudança de perspectiva. É plausível afirmar que a Fundamentação Kant navega em duas esferas ou ordens de argumentação: por um lado, a esfera da justificação (da própria moral via imperativo categórico e dever), embora esta não seja pensada pela perspectiva do paradigma da epistemologia contemporânea (de atribuição de valor de verdade que supõe uma teoria da correspondência); por outro lado, a esfera da objetividade, já que claramente Kant afirma que os juízos morais podem ser corretos ou incorretos porque há uma verdade moral (encarnada no princípio metafísico da autonomia da vontade).

Tendo exposto o horizonte conceptual no qual nos movemos neste artigo, no próximo momento queremos retraçar a argumentação kantiana ao longo das três secções da Fundamentação no sentido de evidenciar a relação entre argumentos éticos e meta-éticos e defender que estes representam preocupações ou pontos de vista distintos mas que, em última análise, se pressupõem mutuamente. Com efeito, o nosso objetivo é mostrar que Fundamentação é um texto riquíssimo para compreender a articulação entre duas dimensões que, a partir do século XX, se têm afirmado como analítica e praticamente distintas, o que sugere a necessária complementaridade entre dois tipos de projetos: um, de fundamentação e justificação de obrigação moral de acordo com um critério determinado; outro, a fundamentação da própria fundamentação, como exercício de uma razão autónoma e que nesse mesmo exercício reconhece a base de todo e qualquer sistema moral.

\section{Reconstruindo a Fundamentação}

Afirmamos no momento anterior que a Fundamentação parece estar suspensa entre um projeto ético-normativo e um projeto meta-ético. Projeto ético-normativo, na medida em que Kant identifica e afirma a existência de uma verdade moral que se apresenta geralmente de forma obscura ao ser humano, já que este é influenciado por desejos e intuições naturais. $\mathrm{O}$ método a priori de análise pretende clarificar, trazer à superfície, a verdade universal que todos os seres humanos têm o potencial de 
reconhecer como "suas", i.e., uma verdade universal que se manifesta no reconhecimento (mesmo que através da postulação) da autonomia individual como exercício concreto da razão. O reconhecimento desta verdade permite-nos determinar como devemos agir, estabelecendo o critério que nos permite diferenciar uma ação moral de uma ação imoral. Por outro lado, a Fundamentação caracteriza simultaneamente, uma posição meta-ética, ao ponto que a postulação desta verdade universal representa o culminar de um processo mais radical de questionamento das condições de possibilidade da própria moral. Neste momento queremos retraçar a argumentação da Fundamentação, ao longo das três seções, para que, neste movimento, se clarifique como os argumentos éticos e meta-éticos estão intricados e se constituem mutuamente.

\section{Da boa vontade à lei moral}

“Neste mundo, e até também fora dele, nada é possível pensar que possa ser considerado como bom sem limitação a não ser uma só coisa: uma boa vontade" (KANT, 2007, p. 21).

Kant começa a primeira secção da Fundamentação com esta afirmação. O Filósofo não define a boa vontade diretamente; esta caracterização é feita a partir de um diálogo com a tradição, nomeadamente com uma ética das virtudes e uma tradição hedonista ou consequencialista. Claramente, Kant começa por responder à questão “O que é o sumo bem?", sem nunca a formular. A boa vontade é a única coisa que é boa sem limitação, ela

[...] não é boa por aquilo que promove ou realiza, pela aptidão para alcançar qualquer finalidade proposta, mas tão-somente pelo querer, isto é, em si mesma, e considerada em si mesma deve ser avaliada em grau muito mais alto do que tudo o que por seu intermédio possa ser alcançado em proveito de qualquer inclinação [...] (KANT, 2007, p. 23, meu itálico).

Sozinha, despida de tudo material, empírico, só a boa vontade "ficaria brilhando por si mesma como uma joia, como alguma coisa que em si mesma tem o seu pleno valor" (idem). 
Kant começa a Fundamentação com a boa vontade por este ser o conceito com o qual todos se podem relacionar na experiencia cotidiana. As primeiras páginas oferecem uma descrição daquilo que já todos sabem, do que é ter uma boa vontade ${ }^{1}$. Porém, embora seja "evidente", é preciso esclarecer e mostrar que a boa vontade não é apenas uma quimera mas algo real, ou seja, Kant quer dar provas da existência da (boa) vontade a partir de um movimento de ascensão da experiência comum a uma metafísica. Para isso, Kant parte da ideia comum de que tudo que é criado tem uma finalidade, para mostrar que o ser humano também tem uma finalidade específica. Se a finalidade do ser humano fosse apenas a sua "conservação, o seu bem-estar, numa palavra, a sua felicidade" (Kant, 2007, p. 24) seria bem mais simples se as ações humanas fossem determinadas apenas pelo instinto, pelo confronto imediato com o mundo natural e pela busca da sua satisfação momentânea. Se a felicidade fosse o fim para o qual o ser humano está destinado, então, poderíamos conceber o ser humano como sendo igualmente determinado pelas leis da natureza, e "a natureza teria evitado que a razão caísse no uso prático e se atrevesse a engendrar com as suas fracas luzes o plano da felicidade e dos meios de a alcançar [...]"(idem). Porém, Kant afirma que reconhecemos imediatamente que a nossa razão tem um uso prático, logo, que a razão, como faculdade especifica do homem, “deve exercer influência sobre a vontade [o que sugere que] o seu verdadeiro destino deverá ser produzir uma vontade não só boa como meio para outra intenção, mas uma vontade boa em si mesma [...]" (Kant, 2007, p. 25). Uma vontade boa em si mesma significa que ela não é um meio para alcançar outra coisa, mas, antes, que ela tem em si o seu próprio fim. Qual o sentido desta afirmação?

Kant começa a analisar os desdobramentos conceptuais a partir da "boa vontade". O primeiro desses desdobramentos dá-se com o conceito de dever. Como diz o autor "o conceito de dever [...] contém em

1 Lembremos que o método de exposição consiste em partir do senso comum para mostrar às pessoas comuns que elas já sabem o que é a moral, apenas se deixam confundir pela competição de inclinações que turva o reconhecimento pessoal do dever. Kant não quer ensinar o que é a moral; ele não quer dizer como devemos viver, porque ele parte do princípio de que todos sabemos o que é; apenas é preciso clarificar e trazer à tona os princípios pelos quais a nossa ação se rege; evidenciar os critérios segundo os quais consideramos uma ação moral. 
si o de boa vontade [...]" (KANT, 2007, p. 26, meu itálico) ou "[o] dever, como dever em geral, anteriormente a toda a experiência, reside na ideia de uma razão que determina a vontade por motivos a priori" (KANT, 2007, p. 41, meu itálico) ${ }^{2}$.

Kant recorre a exemplos no sentido de explicitar o que todos já sabem, i.e., o que é o dever, o que é a moral. Pelos exemplos conseguimos reconhecer algo que transcende os próprios exemplos, a saber, os conceitos puros racionais que constituem a moralidade ${ }^{3}$. Kant diz que:

Todos os conceitos morais têm a sua sede e origem completamente a priori na razão, e isto tanto na razão humana mais vulgar como na especulativa em mais alta medida; que não podem ser abstraídos de nenhum conhecimento empírico e por conseguinte puramente contingente; que exatamente nesta pureza da sua origem reside a sua dignidade para nos servirem de princípios práticos supremos; que cada vez que lhes acrescentemos qualquer coisa de empírico diminuímos em igual medida a sua pura influência e o valor ilimitado das ações; que não só o exige a maior necessidade sob o ponto de vista teórico quando se trata apenas de especulação, mas que é também da maior importância prática tirar da razão pura os seus conceitos e leis, expô-los com pureza e sem mistura, e mesmo determinar o âmbito de todo este conhecimento racional prático mas puro, isto é toda a capacidade da razão pura prática (KANT, 2007, p. 46).

2 Na segunda seç̧ão da Fundamentação Kant explica como o conceito de dever não é um conceito empírico, mas sim a priori; como tal, a experiência nada nos diz nem pode dizer acerca do valor moral da ação; a experiência apenas tem a função de mostrar o que não é como deve ser, i.e., cumpre uma função de negação, sem conseguir confirmar positivamente uma ação por dever. Mas isto gera o problema, encarado com desafio, de mostrar que o conceito de dever não é um conceito vazio ou que por palavras diferentes, é possível superar a aparente aporia quando confrontada com a impossibilidade trazida pela experiência, nomeadamente a de não conseguir corroborar ou verificar a moralidade de uma ação, mas apenas apontar a sua não moralidade, e por outro lado ser capaz de explicar como (e por quê) os conceitos morais têm um significado para nós. Ora, esta explicação acontecerá apenas na terceira secção.

3 Curioso notar que os próprios exemplos têm um carácter paradoxal, na medida em que os exemplos são, por definição, incapazes de retratar de forma plena e justa a moralidade das ações, porque todos os exemplos são empíricos e tudo o que é empírico é necessariamente limitado e parcial, é a objetivação de um princípio universal num "caso" particular. Os exemplos, embora limitados, cumprem a função de guiar, orientar a ação, e sobretudo, a função de esclarecer e de educar acerca da moralidade. 
A partir daqui, Kant entra na discussão do que é a vontade propriamente dita, e afirma claramente que "a vontade não é outra coisa senão razão prática" e "a vontade é a faculdade de escolher só aquilo que a razão, independentemente da inclinação, reconhece como praticamente necessário, quer dizer como bom" (KANT, 2007, p. 47, meu itálico).

Vemos esboçar-se em Kant uma conceptualização de vontade que se define apenas a partir da razão. A diferença entre os seres racionais tout court e os seres humanos é que, os primeiros determinam a vontade apenas pela razão, enquanto, que para os segundos, essa determinação da vontade pela razão é apenas uma possibilidade. Assim, diferentemente dos seres racionais puros entre os quais há uma coincidência com necessidade objetiva e subjetiva, os seres humanos podem agir de acordo com outra coisa que não a razão prática. Em outras palavras, embora as mesmas leis sejam válidas para os seres perfeitos e imperfeitos, há uma diferença na forma como elas se apresentam a uns e a outros. Uma vontade perfeitamente boa só faz o bom, logo, as leis apresentam-se como meras descrições do que é, enquanto que para os seres imperfeitos as leis são prescritivas, elas traduzem-se como mandamentos. Isto explica porque é que os seres humanos têm o conceito de obrigação: a obrigação supõe a obediência (a uma lei), mas encerra em si a constatação de que aquele que é obrigado, é obrigado porque pode ir contra essa obrigação. Assim, a obrigação manifesta-se pela "representação de um princípio objetivo", isto é, um mandamento que se traduz como imperativo. Nas palavras de Kant:

Todos os imperativos se exprimem pelo verbo dever (sollen) e mostram assim a relação de uma lei objetiva da razão para a vontade que segundo a sua constituição subjetiva não é por ela necessariamente determinada (uma obrigação). Eles dizem que seria bom praticar ou deixar de praticar qualquer coisa só porque lhe é representado que seria bom fazê-la. Praticamente bom é porém aquilo que determina a vontade por meio de representações da razão, por conseguinte não por causas subjetivas, mas objetivamente, quer dizer, por princípios que são validos para todo o ser racional como tal (KANT, 2007, p. 48). 
Neste momento, Kant faz a distinção entre imperativos hipotéticos e categóricos, e define o imperativo categórico como aquele que “[...] não se relaciona com a matéria da ação e com o que dela deve resultar, mas com a forma e o princípio do que ela mesmo deriva [...] este imperativo pode-se chamar o imperativo da moralidade" (KANT, 2007, p. 52, meu itálico). Como o imperativo categórico não se apoia em nenhum outro pressuposto e é meramente formal, é impossível dar exemplos empíricos de tal imperativo; ou seja, mais uma vez Kant reforça a tese de que é impossível decidir (ou julgar) a moralidade da ação empiricamente, logo, o desafio consiste na tarefa de investigar, de forma a priori, as condições de possibilidade do imperativo categórico ${ }^{4}$.

O fato do imperativo ser categórico por um lado facilita, mas por outro dificulta a nossa tarefa. Facilita, na medida em que por ser categórico não deixa espaço para dúvidas acerca do que está nele contido; dificulta, na medida em que continuamos com o desafio de explicar porque isto acontece $e$ como é possível justificar a sua existência objetiva (i.e., como fonte de obrigação).

Todo o trabalho da segunda secção da obra visa caracterizar e esclarecer a articulação entre conceitos fundamentais da moral: imperativo categórico (nas suas diferentes formulações), dever, obrigação, máxima, etc., embora a verdadeira tarefa de justificação só se realize na terceira secção.

Na sua formulação principal o imperativo categórico diz: "Age apenas segundo uma máxima tal que possas ao mesmo tempo querer que ela se torne lei universal" (KANT, 2007, p. 59). Não entraremos aqui, na análise sistemática e comparativa das várias formulações apresentadas por Kant. Para o nosso propósito cumpre reforçar a ideia central de que ao apresentar-se o imperativo categórico exclui do horizonte qualquer outra possibilidade que não a necessidade do que ele impõe e ordena. No contexto da segunda formulação - “Age como se a

4 "Só o imperativo categórico tem o caráter de uma lei prática [...]" (KANT, 2007, p. 57). 0 imperativo categórico, enquanto"... mandamento incondicional não deixa à vontade a liberdade de escolha relativamente ao contrário do que ordena, só ele tendo portanto em si aquela necessidade que exigimos na lei" (idem). 
máxima da tua ação se devesse ornar, pela tua vontade, em lei universal da natureza", (idem) - isso significa que

temos que poder querer que uma máxima da nossa ação se transforme em lei universal: é este o cânone pelo qual a julgamos moralmente em geral. Algumas ações são de tal ordem que a sua máxima nem sequer se pode pensar sem contradição como lei universal da natureza, muito menos ainda se pode querer que devam ser tal (KANT, 2007, p. 62).

A consideração de que existem outras alternativas ou possibilidades de ação - o que abriria o campo da exceção válido apenas para nós - deve-se apenas à condição dual da natureza humana, em que nos é possível adoptar dois pontos de vista: o natural (instinto) e o moral (razão). Mas, Kant diz enfaticamente que “[...] se considerássemos tudo partindo de um só ponto de vista, o da razão, encontraríamos uma contradição na nossa própria vontade, a saber: que um certo princípio seja objetivamente necessário como lei universal e que subjetivamente não deva valer universalmente, mas permita exceções" (KANT, 2007, p. 63). Ora, o imperativo categórico, que manifesta de forma absoluta a ordem da lei, gera a obediência a essa lei (i.e., o dever); e essa obediência (ou dever) é a necessidade "prática-incondicionada da ação" (KANT, 2007, p. 64) válida para todos os seres racionais.

Mais uma vez Kant é conduzido à reformulação do problema da obra: como descobrir e mostrar que, primeiramente, a lei moral existe e, em segundo lugar, a lei moral está ligada ao conceito de vontade de um ser racional em geral, de forma totalmente a priori? Kant tenta responder a estas questões, regressando à análise da "vontade".

\section{Vontade, Razão e Objetividade}

“[a] vontade é concebida como a faculdade de se determinar a si mesmo a agir em conformidade com a representação de certas leis. E uma tal faculdade só se pode encontrar em seres racionais" (KANT, 2007, p. 67). 
Vontade e razão são indissociáveis. A vontade é manifestação da razão, capacidade de autodeterminação de acordo com fins objetivos, i.e., válidos para todos os seres racionais (diferentemente dos fins subjetivos que assentam em móbiles). O problema para um leitor do século XXI não reside tanto no fato de Kant conceber a vontade apenas como razão, mas no passo anterior a esse, a saber, na postulação da própria razão. Ao longo do texto, Kant trabalha com a suposição de que existe algo cuja existência tem um valor absoluto como fim em si mesmo. Porém, é exatamente aqui que Kant dá um passo problemático, ao ponto em que ele supõe aquilo que quer provar, a saber, a existência do ser "racional" na qual o ser humano se inclui pela uso prático da razão. Kant tem um desafio impossível: de um lado, ele tem de convencer que este ser racional não só existe como também é fim em si mesmo, i.e., não pode ser usado apenas como meio para outro fim; de outro, que é esse fato do ser racional ser o seu próprio fim que permite construir (postulando, ou reconhecendo) uma esfera autónoma da moral, não redutível a um mero campo de prudência ou destreza.

A partir da definição de ser racional como fim em si mesmo Kant introduz a noção de pessoa, i.e., o termo especificamente moral para o sujeito que se autodetermina e se diferencia da esfera natural ou sensível $^{5}$. Se o ser humano, enquanto ser moral, ou seja, enquanto pessoa, é um fim em si mesmo, então é possível que o fundamento deste princípio seja que "a natureza racional existe como fim em si" (idem). Com isto chegamos à terceira formulação do imperativo categórico: "Age de tal maneira que uses a humanidade, tanto na tua pessoa como na pessoa de qualquer outro, sempre e simultaneamente como fim e nunca simplesmente como meio" (KANT, 2007, p. 69, meu itálico). Este princípio claramente não pode ser extraído da experiência; é um princípio a priori que se constrói na própria definição e constituição da pessoa (ser moral/racional).

Com as várias formulações do imperativo categórico Kant reforça a tese de que a vontade é vontade (e/ou Razão) não apenas porque

5 Enquanto pessoa a sua "existência é em si mesma um fim, e um fim tal que se não pode pôr nenhum outro no seu lugar em relação ao qual essas coisas servissem apenas como meios [...]" (KANT, 2007, p. 68-69). 
está submetida à lei ou porque é motivada pela lei, mas sim porque ela é a criadora da lei que a si mesmo se dá. Dito em outras palavras, a vontade submete-se à lei sem nunca ser submissa, porque ela é autora, legisladora ${ }^{6}$. Se até aqui permanecia por provar a existência do imperativo categórico, porque o dever ainda aparecia como algo externo, a partir do momento em que conceptualizamos o dever como tradução da autonomia do sujeito, i.e., como legislador universal, nos é possível pensar o imperativo categórico, i.e., um imperativo absolutamente incondicionado. Chegamos, assim, ao núcleo duro da argumentação Kantiana: o princípio supremo da moralidade é a autonomia (da vontade). É este princípio que garante e sustenta a possibilidade do imperativo categórico; assim, é este princípio que estabelece o horizonte partilhado por todos os seres racionais (o "Reino dos Fins"), segundo o qual todos estão sistematicamente ligados, porque sujeitos a leis objetivas comuns que definem a relação entre cada um deles (como fim em si e nunca apenas como meio $)^{7}$.

Do ponto de vista meta-ético fica claro que Kant postula uma verdade moral (que se traduz no princípio da autonomia) e, com isso garante o critério normativo que nos permite distinguir ações morais de ações não-morais (a partir do teste das várias formulações do imperativo categórico). Porém, parte do desafio permanece por resolver, a saber, mostrar que é possível um uso sintético da razão (pura) prática.

6 Assim, o princípio, segundo o qual toda a vontade humana seria uma vontade legisladora universal por meio de todas as suas máximas, se fosse seguramente estabelecido, conviria perfeitamente ao imperativo categórico no sentido de que, exatamente por causa da ideia da legislação universal, ele se não funda em nenhum interesse, e portanto, de entre todos os imperativos possíveis, é o único que pode ser incondicional; ou, melhor ainda, invertendo a proposição: se há um imperativo categórico (i.e. uma lei para a vontade de todo o ser racional), ele só pode ordenar que tudo se faça em obediência à máxima de uma vontade que simultaneamente se possa ter a si mesma por objeto como legisladora universal; pois só então é que o princípio prático e o imperativo a que obedece podem ser incondicionais, porque não têm interesse algum sobre que se fundem (Kant, 2007, p. 74).

70 que distingue a natureza racional de todas as outras naturezas é a capacidade que o ser tem de se dar a si mesmo fins, ou seja, de não deixar que a sua vontade se determine por elementos contingentes, utilitaristas ou arbitrários; ao buscar validade universal para a sua máxima, cada ser se identifica com todo 0 outro ser racional e assim, reforça a pertença a um reino dos fins. 


\section{A ideia de liberdade}

Na terceira seção, Kant apresenta a liberdade como a propriedade da vontade, i.e., como uma espécie de "causalidade" que faz com que a vontade se autodetermine apenas segundo a sua ideia. No entanto, Kant está bem ciente de que a ideia de liberdade, que é necessariamente a priori, não pode ser deduzida da razão prática nem pode garantir a possibilidade do imperativo categórico. É preciso que, antes, Kant consiga mostrar que o ser racional só pode agir sob a ideia de liberdade. (KANT, 2007, p. 96), ou seja:

Ela [a razão] tem de considerar-se a si mesma como autora dos seus princípios, independentemente de influências estranhas; por conseguinte, como razão prática ou como vontade de um ser racional, tem de considerarse a si mesma como livre; isto é, a vontade desse ser só pode ser uma vontade própria sob a ideia de liberdade, e, portanto, é preciso atribuir, em sentido pratico, uma tal vontade a todos os seres racionais (KANT, 2007, p. 96) .

Claro que Kant ainda não conseguiu explicar por que agimos sob a ideia de liberdade. Ele apenas afirma, tentando convencer-nos de que a não ser que postulemos a ideia de liberdade não conseguiremos pensar os seres racionais como dotados de uma vontade, ou dito por outras palavras, não conseguiremos sequer pensar a "razão". O desafio continua: mesmo supondo a ideia de liberdade e aceitando que só esta constitui o princípio da vontade, como provar que a lei moral, de fato, obriga?

O problema com a argumentação de Kant é que a sua resposta não parece convincente dizendo que estamos sujeitos à lei moral (e somos obrigados por ela) porque somos livres, e somos livres a ideia de liberdade que se expressa no princípio de autonomia é reconhecida e identificada por nós. De onde deriva a necessidade de auto (re)conhecimento enquanto ser livre e racional? A não ser que consigamos responder a esta questão, torna-se impossível garantir a validade dos próprios mandamentos morais. Para respondê-la, e assim revolver o problema da validade e da justificação, Kant introduz a distinção entre mundo sensível e mundo inteligível. Segundo ele, 
o ser racional, como inteligência, conta-se como pertencente ao mundo inteligível, e só chama vontade à sua causalidade como causa eficiente que pertence a esse mundo inteligível. Por outro lado tem ele consciência de si mesmo como parte também do mundo sensível, no qual as suas ações se encontram como meros fenómenos daquela causalidade; mas a possibilidade dessas ações não pode ser compreendida por essa causalidade, que não conhecemos, senão que em seu lugar têm aquelas ações que são compreendidas como pertencentes ao mundo sensível, como determinadas por outros fenómenos, a saber: apetites e inclinações. Se eu fosse um mero membro do mundo inteligível, todas as minhas ações seriam perfeitamente conformes ao princípio da autonomia da vontade pura; mas como mera parte do mundo sensível, elas teriam de ser tomadas como totalmente conformes à lei natural dos apetites e inclinações, por conseguinte, à heteronomia da natureza (KANT, 2007, p. 103).

O homem pertence a dois mundos: ao mundo natural ou sensível e ao mundo inteligível ou suprassensível. Isso faz com que ele esteja sujeito a dois tipos de causalidade: a causalidade da natureza e a causalidade da vontade. Na medida em que pertence a duas ordens distintas, é preciso demonstrar antes como a ligação entre os mundos se torna possível ou, por outras palavras, como é possível pensar a liberdade da ação humana, i.e., uma ação que não reflita apenas o determinismo natural. Só é possível pensar a liberdade se supusermos primeiro que "o mundo inteligível contém o fundamento do mundo sensível, e portanto também das suas leis" (KANT, 2007, p. 104). De alguma forma, a própria possibilidade de pensar a liberdade coexiste, ou dá-se em simultâneo, com o (re)conhecimento ou postulação da sua necessidade. Neste caso, o princípio da autonomia - princípio metafísico que define essencialmente o homem, enquanto ser racional - é a tradução ou manifestação literal da própria ideia de liberdade ${ }^{8}$. A ideia de liberdade é já, segundo Kant nesta obra específica, prova da sua existência. Ao mesmo tempo,

8 Como o ser humano é um ser dual, isto é, um ser pertencente a dois mundos, ele representa a convergência de duas lógicas ou causalidades que podem não estar em sintonia. Se 0 homem fosse ser racional apenas todas as suas ações seriam livres, isto é, "perfeitamente conformes ao princípio da autonomia da vontade pura"; mas como 0 homem não é vontade pura mas apenas vontade, ele tem que aceitar as leis do mundo inteligível como imperativos, i.e., como ordens que orientam a determinação da vontade de acordo com a causalidade da liberdade e assim, resistindo e/ou opondo-se à heteronomia da natureza. 
ela manifesta-se no imperativo categórico que, segundo o autor, é uma proposição sintética a priori na medida em que articula a pertença do sujeito a dois mundos distintos e manifesta a primazia de um sobre o outro. O dever nada mais é do que a tradução da consciência do sujeito de que ele é membro do mundo sensível, mas quer afirmar-se como ser inteligível e livre.

Chegamos assim, à reta final da argumentação kantiana. A liberdade, obviamente, não é nem pode ser um conceito da experiência, mas ela é condição suficiente de autonomia individual, e isto é o limite da dedução kantiana. Qualquer tentativa de provar de forma mais sistemática a realidade da liberdade ou a existência fatual do imperativo categórico está condenada ao fracasso (do ponto de vista positivista). Como diz Kant "a liberdade é apenas uma ideia da razão cuja realidade objetiva é em si duvidosa" (KANT, 2007, p. 106). Não é possível explicar como a razão pura pode ser prática, nem como é possível a liberdade, já que "a liberdade é uma mera ideia cuja realidade objetiva não pode ser de modo algum exposta segundo leis naturais, e portanto, em nenhuma experiência também, que, por consequência, uma vez que nunca se lhe pode subpor um exemplo por nenhuma analogia, nunca pode ser concebida nem sequer conhecida" (KANT, 2007, p. 111). A liberdade é um "pressuposto necessário da razão", é condição necessária para que o sujeito se pense a si mesmo como pessoa livre e autónoma, como capaz de resistir, superar, transformar a ordem da causalidade natural.

Em defesa de Kant, poderíamos dizer que o fato de que as máximas podem ser livremente escolhidas pelo sujeito é já prova suficiente de que estas não pertencem à relação causa-efeito do mundo natural, remetendo-nos por isso a uma ordem distinta e superior. Em última análise, o percurso traçado por Kant visa mostrar que "o conceito de um mundo inteligível é portanto apenas um ponto de vista que a razão se vê forçada a tomar fora dos fenómenos para se pensar a si mesma como prática" (KANT, 2007, p. 110). 


\section{Considerações finais}

Na Fundamentação Kant adota o método analítico nas duas primeiras secções, e o método sintético na terceira secção. Por que a distinção de método? As secções analíticas pretendem identificar ou descobrir o princípio supremo da moralidade e as suas variações, para depois serem confirmadas ou justificadas na última secção. Por que é que a justificação tem de ser sintética? De acordo com Kant, os princípios a priori são analíticos ou sintéticos. O princípio supremo da moralidade, se é a priori, não pode ter uma fundação analítica, na medida em que a análise dos conceitos nos ajuda a compreendê-los melhor mas não conseguem, por si só, estabelecer a sua realidade. Dito por outras palavras, Kant está perfeitamente consciente de que os juízos analíticos clarificam os conceitos mas são incapazes de determinar a sua validade, e é a validade que Kant quer assegurar na Fundamentação. Assim, o objetivo de Kant é conseguir justificar o uso dos nossos princípios sintéticos a priori, pois só dando este passo é possível afirmar que as ideias (nomeadamente, a ideia de liberdade) correspondem a algo real e que quando falamos (de questões morais) as nossas expressões têm um sentido objetivo. Foi por esta razão que na $C R P$ Kant precisou proceder a uma dedução das categorias, na medida em que elas não nos são dadas na experiência. A nível da razão prática, Kant mostra na última secção da Fundamentação que é possível aplicar o conceito de dever à ação humana, mostrando que o princípio do dever - quer na aparência do imperativo categórico, quer na sua variante mais metafísica, no princípio da autonomia - é um princípio sintético a priori. Quais as implicações deste passo? Por um lado, afirma a distinção insuperável entre mundo dos fatos, da experiência $e$ mundo dos valores ou normas. Por outro lado, apesar do abismo entre as duas ordens que conduz à constatação de que o mundo da experiência não pode ser a fonte de autoridade da lei moral, Kant abre espaço para conceber a obrigação moral a partir do imperativo categórico.

O imperativo é uma ordem (para agir), uma proposição sintética a priori, porque diz ao agente para fazer algo novo, ou seja, algo que não está contido em si mesmo mas se abre para o mundo. Claro que 
levanta-se aqui um outro problema, caro às discussões contemporâneas, a saber, como é possível pensar em razões externas à ação? Como é que a razão, por si mesma, é capaz de motivar? Podemos antecipar que este é o grande problema e que Kant só consegue manter e conferir um sentido objetivo ao conceito de dever supondo que a razão tem esta capacidade de motivar, já que o conceito de dever, tal como o conceito de autonomia, são a priori e por isso não são passiveis de corroboração pela experiência. A experiência, aliás, fornece apenas dados concretos que contrariam a postulação desse dever e autonomia, já que mostra em que medida os seres humanos estão sujeitos a leis naturais, logo, não são livres. Porém, a Crítica da Razão Pura abriu já, a possibilidade de conciliar ou articular o domínio do determinismo natural com o domínio da liberdade. Nesta medida, devemos entender uma investigação crítica sobre a razão prática como uma investigação que visa estabelecer se e como há ações que são independentes da experiência. Explicar como os juízos sintéticos a priori são possíveis define a tarefa da segunda crítica da razão pura.

\section{Referências}

KANT, I. Fundamentação da metafísica dos costumes. Trad. Paulo Quintela. Lisboa: Edições 70, 2007.

KANT, I. Crítica da razão pura. Trad. Manuela Pinto dos Santos e Alexandre Fradique Morujão. Lisboa: Fundação Calouste Gulbenkian, 1994.

MOORE, G. E. Principia Ethica. Cambridge: Cambridge University Press, 1993. MILLER, A. An introduction to contemporary metaethics. Londres: Polity Press, 2003.

Recebido: 21/03/2016

Received: 03/21/2016

Aprovado: 03/06/2016

Approved: 06/03/2016 